\title{
ON THE $M^{\mathrm{X}} / \mathrm{G} / 1$ QUEUE WITH AND WITHOUT VACATION TIME UNDER NONPREEMPTIVE LAST-COME FIRST-SERVED DISCIPLINE
}

\author{
Yutaka Baba \\ Chubu University
}

(Received February 3, 1986; Final February 14, 1987)

\begin{abstract}
We consider the $M^{X} / G / 1$ queue with and without vacation time under nonpreemptive last-come first-served (LCFS). The Laplace Stieltjes transform of the distribution function of the steady-state waiting time is found. The first two moments of the waiting time are obtained. We find the relationship between the second moments of the waiting time in the $M^{X} / G / 1$ queue with and without vacation time under first-come first-served (FCFS) and LCFS.
\end{abstract}

Key words: $M^{X} / G / 1$ queue, vacation time, last-come first-served, waiting time

\section{Introduction}

In this paper, we study the batch arrival $M^{X} / G / 1$ queue with and without vacation time under nonpreemptive last-come first-served (LCFS).

In some queueing systems, the server takes a vacation of random length each time the system becomes empty. The vacation time is utilized for some additional work. If the server returns from a vacation and he finds one or more customers waiting, he works until the system empties, then takes another vacation. if the server returns from a vacation and finds no customers waiting, he takes another vacation immediately. 
The $M / G / 1$ queue with vacation time has been studied by a number of authors, e. $g$. Cooper [5], Levy and Yechiali [9], Scholl and Kleinrock [10]. In particular [10] has studied the waiting time of the $M / G / 1$ queue with vacation time under three queveing disciplines, which are independent of service time: first-come first-served (FCFS), random order of service (ROS) and nonpreemptive LCFS.

Several authors have studied the batch arrival queueing system $M^{x} / G / 1$ under FCFS (see Chaudhry [3], Chaudhry and Templeton [4], Cooper [6], Gross and Harris [7] and Kleinrock [8]). Recently Baba [1] has studied the $M^{X} / G / 1$ queue with vacation time under FCFS. However, there has been no work for the $M^{X} / G / 1$ queue with vacation time under other service discipline.

Nonpreemptive LCFS queueing discipline is applicable to many practical situations such as push-down stack and inventory systems, etc. The batch arrival queueing model appears in many situations such as computer communication systems. So it is important to analyze the model that will be studied in this paper. In the batch arrival queueing systerns under nonpreemptive LCFS, the following two queueing disciplines are considered.

(1) Queueing discipline 1

The customers which are included in the same batch as the customer in service are served previously than the customers which arrived at the system after the customer in service. (This discipline is considered as the case that arrived batch is treated as a super customer)

(2) Queueing discipline 2

The order of service is nonpreemptive LCFS with respect to batches and the order of service in a batch is random. (This discipline is considered as the nonpreemptive LCFS discipline with respect to all customers in the system)

In this paper, we study the queueing system under queueing discipline 2. This paper studies Laplace Stieltjes teansform (LST) of the distribution function (d. f.) of the steady-state waiting time for the $M^{x} / G / 1$ queue with and without vacation time under nonpreemptive LCFS. The first two moments of the waiting time are obtained.

The relationship that we find in this paper between the second moments of the waiting time for FCFS and LCFS in the $M^{x} / G / 1$ queue with and without vacation time is an 
extension of the result which has been found in [10] in the $M / G / 1$ queue with and without vacation time.

\section{Assumptions and Notations}

We consider the $M^{X} / G / 1$ queue with and without vacation time. We study this queueing system under queueing discipline 2 stated in Section 1 . For the $M^{x} / G / 1$ queue, it is assumed that customers arrive in batches according to a time homogeneous Poisson process with rate $\lambda$. The batch size $X$ is a random variable and

$$
P(X=n)=g_{n}, \quad n=1,2, \ldots
$$

with probability generating function (p. g. f.)

$$
G(z)=\sum_{k=1}^{\infty} g_{k} z^{k} \quad|z| \leq 1
$$

We assume that $n$-th $(n=1,2,3)$ factorial moments of $X$ are finite and defined by

$$
\begin{aligned}
g & =E(X)=G^{(1)}(1) \\
g^{(2)} & =E(X(X-1))=G^{(2)}(1) \\
g^{(3)} & =E(X(X-1)(X-2))=G^{(3)}(1) .
\end{aligned}
$$

Let $S(x)$ be the d. f. of the service time $S$ of a typical customer and $S^{*}(\theta)$ be the LST of $S$. Denote by $\hat{S}$ the remaining service time for the customer in service. The d. f. $\hat{S}(x)$ and the $\operatorname{LST} \hat{S}^{*}(\theta)$ of $S$ are given by (see [8])

$$
\begin{aligned}
\hat{S}(x) & =\frac{1}{E(S)} \int_{0}^{x}[1-S(t)] d t, \\
\hat{S}^{*}(\theta) & =\left[1-S^{*}(\theta)\right] / \theta E(S) .
\end{aligned}
$$

In order to analyze the queue with vacation time, we denote by $V(x)$ the $d$. $f$. of a typical vacation time $V$ and $V^{*}(\theta)$ the LST of $V$. Further denote by $\hat{V}$ the remaining vacation time for the server on vacation. The d. f. $\hat{V}(x)$ and the LST $\hat{V}^{*}(\theta)$ of $\hat{V}$ are

$$
\begin{aligned}
\hat{V}(x) & =\frac{1}{E(V)} \int_{0}^{x}[1-V(t)] d t, \\
\hat{V}^{*}(\theta) & =\left[1-V^{*}(\theta)\right] / \theta E(V) .
\end{aligned}
$$


Let $B$ be the random variable of busy period that starts with one customer. The busy period starts with one customer is called 1-busy period. Denote by $B(x)$ the $d$. $f$. of the random variable $B$ and denoted by $B^{*}(\theta)$ the LST of $B$. Suppose that a 1-busy period starts by one customer and its service time $S_{1}=x$. Let $N_{1}$ be the number of customer arrivals during the interval $S_{1}$. By conditioning on $S_{1}$ and $N_{1}$, we have the following conditional transform

$$
E\left(e^{-\theta B} \mid S_{1}=x, N_{1}=n\right)=e^{-\theta x}\left[B^{\prime \prime}(\theta)\right]^{n} .
$$

Unconditioning on $N_{1}$, we have

$$
\begin{aligned}
E\left(e^{-\theta B} \mid S_{1}=x\right) & =\sum_{n=0}^{\infty} E\left(e^{-\theta B} \mid S_{1}=x, N_{1}=n\right) P\left(N_{1}=n\right) \\
& =\sum_{\boldsymbol{n}=\boldsymbol{0}}^{\infty} e^{-\theta x}\left[B^{*}(\theta)\right]^{\boldsymbol{n}} \sum_{k=0}^{\boldsymbol{n}} \frac{(\lambda x)^{\boldsymbol{k}}}{k !} g_{\boldsymbol{n}}^{* \boldsymbol{k}} e^{-\lambda x} \\
& =\exp \left[-\left\{\theta+\lambda-\lambda G\left(B^{*}(\theta)\right)\right\} x\right]
\end{aligned}
$$

where $g_{n}^{* k}$ is the $k$-fold convolution of $g_{n}$ with itself, with $g_{i}^{* 0}=\delta_{i 0}$. Finally we have

$$
\begin{aligned}
B^{*}(\theta) & =E\left(e^{-\theta B}\right) \\
& =\int_{0}^{\infty} \exp \left[-\left\{\theta+\lambda-\lambda G\left(B^{*}(\theta)\right)\right\} x\right] d S(x) \\
& =S^{*}\left(\theta+\lambda-\lambda G\left(B^{*}(\theta)\right)\right)
\end{aligned}
$$

In the case of the traffic intensity $\rho=\lambda g E(S)<1$, the $n$-th $(n=1,2,3)$ moments of $B(x)$ are given by

$$
\begin{aligned}
E(B) & =E(S) /(1-\rho) \\
E\left(B^{2}\right) & =\frac{E\left(S^{2}\right)+\lambda g^{(2)}[E(S)]^{3}}{(1-\rho)^{3}} \\
E\left(B^{3}\right) & =\frac{E\left(S^{3}\right)+\lambda g^{(3)}[E(S)]^{4}}{(1-\rho)^{4}} \\
& +\frac{3 \lambda g\left[E\left(S^{2}\right)\right]^{2}+6 \lambda g^{(2)}[E(S)]^{2} E\left(S^{2}\right)+3 \lambda\left[g^{(2)}\right]^{2}[E(S)]^{5}}{(1-\rho)^{5}}
\end{aligned}
$$

\section{$3 \quad$ Waiting Time Distribution}

\subsection{The $M^{X} / G / 1$ Queue without Vacation Time under LCFS}


Let $r_{n}(n=1,2, \ldots)$ be the probability of an arbitrary customer being in the $n$-th position of an arrived batch. Burke [2] showed, using a result in the renewal theory, that it is given by

$$
r_{x}=\frac{1}{g} \sum_{k=n}^{\infty} g_{k}
$$

Define the p. g. f.

$$
R(z)=\sum_{n=1}^{\infty} r_{n} z^{n}=\frac{z[1-G(z)]}{g(1-z)} .
$$

At the time of an arbitrary test customer's arrival, there will be a number of customers arriving in his batch who will be served before him. This number is $(n-1)$ with probability $r_{x}$.

Suppose that an arbitrary test customer named $C_{0}$ arrives when the server is idle. the $(n-1)$ customers arriving in $C_{0}$ 's batch who will be served before him are named $C_{1}, \ldots, C_{n-1}$, respectively. Observe that the effect of $C_{i}(i=1, \ldots, n-1)$ on the waiting time of $C_{0}$ is the 1-busy period $B_{i}$ generated by $C_{i}$. Since $B_{1}, \ldots, B_{n-1}$ are mutually independent and the proportion of time that the server is idle in an $M^{x} / G / 1$ queue is $1-\rho$ (see e. g. [3]), the steady-state waiting time of $C_{0}$ is distributed as $B_{1}+\cdots+B_{n-1}$ with probability $(1-\rho) r_{n}$. Next suppose that $C_{0}$ arrives when the server is busy. Let the remaining service time of the customer in service at $C_{0}$ 's arrival epoch be $\hat{S}$. Suppose that $m$ (a random variable) customers named $C_{n}, \ldots, C_{m+-1}$ arrive during $\hat{S}$. Denote by $B_{*}$ $(i=1, \ldots, m+n-1)$ the 1 -busy period generated by $C_{i}$. Similar to the case that the server is idle, the steady-state waiting time of $C_{0}$ is distributed as $B_{1}+\cdots+B_{n-1}+B_{x}+\cdots+B_{m+n-1}$ with probability $\rho r_{n}$. Let $W_{L}$ and $W_{L}^{*}(\theta)$ be the steady-state waiting time of an arbitrary customer and its LST, respectively. Since $B_{1}, \ldots, B_{n-1}$ are independent of $\hat{S}$, we have

$$
\begin{aligned}
& W_{L}^{*}(\theta)=\sum_{\boldsymbol{x}=1}^{\infty}(1-\rho) r_{\boldsymbol{x}}\left[B^{*}(\theta)\right]^{\boldsymbol{n}-1} \\
& +\sum_{n=1}^{\infty} \rho r_{n} \sum_{m=0}^{\infty} \sum_{k=0}^{m}\left[B^{*}(\theta)\right]^{m+n-1} \int_{0}^{\infty} \frac{(\lambda t)^{k}}{k !} e^{-(\lambda+\theta) s} g_{m}^{m k} d \hat{S}(t) \\
& =\frac{(1-\rho) R\left(B^{*}(\theta)\right)}{B^{*}(\theta)}+\sum_{\boldsymbol{n}=1}^{\infty} \rho r_{\boldsymbol{n}}\left[B^{*}(\theta)\right] x^{\boldsymbol{n}-1} \hat{S}^{*}\left(\theta+\lambda-\lambda G\left(B^{*}(\theta)\right)\right) \\
& =\frac{(1-\rho)\left[1-G\left(B^{*}(\theta)\right)\right]}{g\left[1-B^{*}(\theta)\right]}+\frac{\lambda\left[1-G\left(B^{*}(\theta)\right)\right]}{\theta+\lambda-\lambda G\left(B^{*}(\theta)\right)}
\end{aligned}
$$


By taking the first and second derivatives of (18) at $\theta=0$, we obtain the following expressions:

$$
\begin{aligned}
E\left(W_{L}\right) & =\frac{(1-\rho) g^{(2)} E(B)}{2 g}+\frac{\lambda g^{(2)}[E(B)]^{2}+\lambda g E\left(B^{2}\right)}{2[1+\lambda g E(B)]^{2}} \\
& =\frac{\lambda g E\left(S^{2}\right)}{2(1-\rho)}+\frac{g^{(2)} E(S)}{2 g(1-\rho)} \\
E\left(W_{L}^{2}\right) & =\frac{(1-\rho)}{6 g}\left[3 g^{(2)} E\left(B^{2}\right)+2 g^{(3)}\{E(B)\}^{2}\right] \\
& +\frac{\lambda}{6[1+\lambda g E(B)]^{3}}\left[2 [ 1 + \lambda g E ( B ) ] \left[g^{(3)}\{E(B)\}^{3}\right.\right. \\
& \left.+3 g^{(2)} E(B) E\left(B^{2}\right)+g\left(B^{3}\right)\right] \\
& \left.-3 \lambda\left[g^{(2)}\{E(B)\}^{2}+g E\left(B^{2}\right)\right]^{2}\right] \\
& =\frac{\lambda g E\left(S^{3}\right)}{3(1-\rho)^{2}}+\frac{\lambda^{2} g^{2}\left\{E\left(S^{2}\right)\right\}^{2}}{2(1-\rho)^{3}}+\frac{g^{(3)}\{E(S)\}^{2}}{3 g(1-\rho)^{2}} \\
& +\frac{\lambda\left\{g^{(2)}\right\}^{2}\{E(S)\}^{3}+(1+\rho) g^{(2)} E\left(S^{2}\right)}{2 g(1-\rho)^{3}}
\end{aligned}
$$

Remark 1. Let $W_{F}$ be the steady-state waiting time without vacation time when the service discipline is FCFS. Its LST, $W_{F}^{*}(\theta)$, is given by (see Cooper [6])

$$
W_{F}^{*}(\theta)=\frac{(1-\rho) \theta\left[1-G\left(S^{*}(\theta)\right)\right]}{g\left[\theta-\lambda+\lambda G\left(S^{*}(\theta)\right)\right]\left[1-S^{*}(\theta)\right]} .
$$

By taking the first and second derivatives of (21) at $\theta=0$, we have

$$
\begin{aligned}
E\left(W_{F}\right) & =\frac{\lambda g E\left(S^{2}\right)}{2(1-\rho)}+\frac{g^{(2)} E(S)}{2 g(1-\rho)} \\
E\left(W_{F}^{2}\right) & =\frac{\lambda g E\left(S^{3}\right)}{3(1-\rho)}+\frac{\lambda^{2} g^{2}\left\{E\left(S^{2}\right)\right\}^{2}}{2(1-\rho)^{2}}+\frac{g^{(3)}\{E(S)\}^{2}}{3 g(1-\rho)} \\
& +\frac{\lambda\left\{g^{(2)}\right\}^{2}\{E(S)\}^{3}+(1+\rho) g^{(2)} E\left(S^{2}\right)}{2 g(1-\rho)^{2}}
\end{aligned}
$$

Since the order of service is independent of service time, we see immediately that the mean queue size and the mean waiting time for LCFS must be same as for FCFS. Thus it is clear that $E\left(W_{L}\right)=E\left(W_{F}\right)$ seen from (19) and (22). However, the second moment $E\left(W_{L}^{2}\right)$ is larger than $E\left(W_{F}^{2}\right)$. Comparing (20) to (23), we have

$$
E\left(W_{L}^{2}\right)=E\left(W_{F}^{2}\right) /(1-\rho)
$$

It is surprising to find that this result holds for the $M^{x} / G / 1$ queue as well as for the $M / G / 1$ queue. 


\subsection{The $M^{X} / G / 1$ Queue with Vacation Time under LCFS}

As is the case with 3.1, since the proportion of time that the server is vacationing in the $M^{X} / G / 1$ queue with vacation time is $1-\rho$ (see Baba [1]), the steady-state waiting time of an arbitrary test customer is distributed as $\hat{V}+B_{1}+\cdots+B_{m+n-1}$ with probability $(1-\rho) r_{n}$, where $m$ is the number of customers arrived during the residual vacation time hat $V$ and as $\hat{S}+B_{1}+\cdots+B_{m+n-1}$ with probability $\rho r_{n}$, where $m$ is the number of customers arrived during the residual service time $\hat{S}$. Let $W_{V L}$ and $W_{V L}^{*}(\theta)$ be the steady-state waiting time of an arbitrary customer and its LST, respectively. By using ( 7$)$ and (17), we have

$$
\begin{aligned}
& W_{V L}^{*}(\theta)=\sum_{n=1}^{\infty}(1-\rho) r_{\boldsymbol{n}} \sum_{m=0}^{\infty} \sum_{k=0}^{m}\left[B^{*}(\theta)\right]^{\boldsymbol{m}+\boldsymbol{k}-1} \int_{0}^{\infty} \frac{(\lambda t)^{k}}{k !} e^{-(\lambda+\theta) t} g_{m}^{* k} d \hat{V}(t) \\
& +\sum_{n=1}^{\infty} \rho r_{n} \sum_{m=0}^{\infty} \sum_{k=0}^{m}\left[B^{*}(\theta)\right]^{n+1-1} \int_{0}^{\infty} \frac{(\lambda t)^{k}}{k !} e^{-(\lambda+\theta) t} g_{m}^{* k} d \hat{S}(t) \\
& =\sum_{n=1}^{\infty}(1-\rho) r_{n}\left[B^{*}(\theta)\right]^{n-1} \hat{V}\left(\theta+\lambda-\lambda G\left(B^{*}(\theta)\right)\right) \\
& +\sum_{n=1}^{\infty} \rho r_{n}\left[B^{*}(\theta)\right]^{n-1} \hat{S}^{*}\left(\theta+\lambda-\lambda G\left(B^{*}(\theta)\right)\right) \\
& =\frac{(1-\rho)\left[1-V^{*}\left(\theta+\lambda-\lambda G\left(B^{*}(\theta)\right)\right)\right] R\left(B^{*}(\theta)\right)}{B^{*}(\theta)\left[\theta+\lambda-\lambda G\left(B^{*}(\theta)\right)\right] E(V)} \\
& +\frac{\rho\left[1-S^{*}\left(\theta+\lambda-\lambda G\left(B^{*}(\theta)\right)\right)\right] R\left(B^{*}(\theta)\right)}{B^{*}(\theta)\left[\theta+\lambda-\lambda G\left(B^{*}(\theta)\right)\right] E(S)} \\
& =\frac{(1-\rho)\left[1-V^{*}\left(\theta+\lambda-\lambda G\left(B^{*}(\theta)\right)\right)\right]\left[1-G\left(B^{*}(\theta)\right)\right]}{g\left[1-B^{*}(\theta)\right]\left[\theta+\lambda-\lambda G\left(B^{*}(\theta)\right)\right] E(V)} \\
& +\frac{\lambda\left[1-G\left(B^{*}(\theta)\right)\right]}{\theta+\lambda-\lambda G\left(B^{*}(\theta)\right)}
\end{aligned}
$$

By taking the first and second derivatives of (25) at $\theta=0$, we have

$$
\begin{aligned}
E\left(W_{V L}\right) & =\frac{E\left(V^{2}\right)}{2 E(V)}+\frac{\lambda g E\left(S^{2}\right)}{2(1-\rho)}+\frac{g^{(2)} E(S)}{2 g(1-\rho)} \\
E\left(W_{V L}^{2}\right) & =\frac{g^{(2)} E(S) E\left(V^{2}\right)}{2 g(1-\rho)^{2} E(V)}+\frac{E\left(V^{3}\right)}{3(1-\rho) E(V)}+\frac{\lambda g E\left(S^{2}\right) E\left(V^{2}\right)}{2(1-\rho)^{2} E(V)} \\
& +\frac{\lambda g E\left(S^{3}\right)}{3(1-\rho)^{2}}+\frac{\lambda^{2} g^{2}\left[E\left(S^{2}\right)\right]^{2}}{2(1-\rho)^{3}}+\frac{g^{(3)}[E(S)]^{2}}{3 g(1-\rho)^{2}} \\
& +\frac{\lambda\left[g^{(2)}\right]^{2}[E(S)]^{3}+(1+\rho) g^{(2)} E\left(S^{2}\right)}{2 g(1-\rho)^{3}}
\end{aligned}
$$

Remark 2. Let $W_{V F}$ be the waiting time with vacation time when the service discipline is FCFS. Its LST, $W_{V F}^{*}(\theta)$, is given by (see [1]) 


$$
W_{V F}^{*}(\theta)=\frac{(1-\rho)\left[1-G\left(S^{*}(\theta)\right)\right]\left[1-V^{*}(\theta)\right]}{g\left[\theta-\lambda+\lambda G\left(S^{*}(\theta)\right]\left[1-S^{*}(\theta)\right] E(V)\right.} .
$$

By taking the first and second dervatives of (28) at $\theta=0$, we have

$$
\begin{aligned}
E\left(W_{V F}\right) & =\frac{E\left(V^{2}\right)}{2 E(V)}+\frac{\lambda g E\left(S^{2}\right)}{2(1-\rho)}+\frac{g^{(2)} E(S)}{2 g(1-\rho)} \\
E\left(W_{V F}^{2}\right) & =\frac{g^{(2)} E(S) E\left(V^{2}\right)}{2 g(1-\rho) E(V)}+\frac{E\left(V^{3}\right)}{3 E(V)}+\frac{\lambda g E\left(S^{2}\right) E\left(V^{2}\right)}{2(1-\rho) E(V)} \\
& +\frac{\lambda g E\left(S^{3}\right)}{3(1-\rho)}+\frac{\lambda^{2} g^{2}\left[E\left(S^{2}\right)\right]^{2}}{2(1-\rho)^{2}}+\frac{g^{(3)}[E(S)]^{2}}{3 g(1-\rho)} \\
& +\frac{\lambda\left[g^{(2)}\right]^{2}[E(S)]^{3}+(1+\rho) g^{(2)} E\left(S^{2}\right)}{2 g(1-\rho)^{2}}
\end{aligned}
$$

As is the case with 3.1 , it holds that $E\left(W_{V L}\right)=E\left(W_{V F}\right)$ and $E\left(W_{V L}^{2}\right)=E\left(W_{V F}^{2}\right) /(1-\rho)$.

\section{Conclusion}

We have studied the waiting time of the $M^{X} / G / 1$ queue without and with vacation time under nonpreemptive LCFS. Comparing to FCFS, we have shown that

$$
\begin{aligned}
E\left(W_{L}\right) & =E\left(W_{F}\right), \\
E\left(W_{L}^{2}\right) & =E\left(W_{F}^{2}\right) /(1-\rho), \\
E\left(W_{V L}\right) & =E\left(W_{V F}\right) \\
E\left(W_{V L}^{2}\right) & =E\left(W_{V F}^{2}\right) /(1-\rho) .
\end{aligned}
$$

For the $M / G / 1$ queue, equation (31)-(34) hold (see [10]). The results obtained in this paper is the extension to the batch arrival $M^{X} / G / 1$ queue.

\section{References}

[1] Baba, Y.: On the $M^{X} / G / 1$ Queve with Vacation Time. Operations Research Letters, Vol.5 (1986), 93-98.

[2] Burke, P. J.: Delays in Single-Server Queues with Batch Input. Operations Research, Vol.23 (1975), 830-833. 
[3] Chandhry, M. L.: The Queueing System $M^{X} / G / 1$ and Its Ramifications. Naval Research Logistics Quaterly, Vol.26 (1979), 667-674.

[4] Chaudhry, M. L. and Templeton, J. G. C: A first Course in Bulk Queues. John Wiley and Sons, New York, 1983.

[5] Cooper, R. B.: Queues Served in Cyclic Order: Waiting Times. Bell System Technical Journal, Vol.49 (1970), 399-413.

[6] Cooper, R. B.: Introduction to Queueing Theory, 2nd ed. Elsevier North Holland, New York, 1981.

[7] Gross, D. and Harris, C. M.: Fundamentals of Queueing Theory, 2nd ed. John Wiley and Sons, New York, 1985.

[8] Kleinrock, L.: Queueing Systems, Vol. 1. Theory. John Wiley and Sons, New York, 1975.

[9] Levy, Y. and Yechiali, Y.: Utilization of Idle Time in an $M / G / 1$ Queueing System. Management Science, Vol.22 (1975), 202-211.

[10] Scholl, M. and Kleinrock, L.: On the $M / G / 1$ Queue with Rest Period and Certain Service-Independent Queueing Disciplines. Operations Research, Vol.31 (1983), 705-719.

Yutaka BABA: Department of Business Administration and Information Science, Chubu University, Kasugai, Aichi, 487, Japan. 


\section{バケーションタイムをもつ（もたない）非割り込み形 後着順サービス待ち行列 $M^{x} / G / 1$ について}

本論文では，非割り込み形後着順サービス規律（LCFS）をむつ集団到着待ち行列 $M^{x} / G / 1$ をバ ケーションタイムをあつ場合ともたない場合について解析し, 定常状態における待ち時間のラプラス ・スティルチェス変換を求める。待ち時間のラプラス・スティルチェス変換より2次までのモーメン 卜を求め, 先着順サービス規律 (FCFS) をもつ $M^{x} / G / 1$ との比較京行う。

その結果, バケーションタイムをもつ場合ともたない場合のいずれの場合に拈いても，L C F S と F C F S 亿抢ける2次モーメント間の関係が簡単な式で表され, Scholl and Kleinrockが M/G/1 の場合について求めた結果と本論文で求められた $M * / G / 1$ の結果が同じであるととがわかる。すな わち $M / G / 1$ で成り立つモーメント間の関係式が $M^{x} / G / 1$ でも成り立つととがわかる。 